\title{
Evaluation of mineral fiber properties using $x-$ ray fluorescence analysis and measurement of natural radioactivity
}

\author{
Andrey Medvedev ${ }^{1 *}$, Ekaterina Bobrova ${ }^{2}$, Alexey Poserenin ${ }^{3}$ and Ervand Zarmanyan ${ }^{1}$ \\ ${ }^{1}$ Moscow State University of Civil Engineering, 129337, Yaroslavskoye shosse, 26, Moscow, Russia \\ ${ }^{2}$ Higher School of Economics, 101000, Myasnitskaya str. 20, Moscow, Russia \\ ${ }^{3}$ Russian State Geological Prospecting University, 117997, Miklukcho-Maklaya, 23, Moscow, Russia
}

\begin{abstract}
The article analyzes the factors affecting the longevity of insulating systems and the operational resistance of products based on mineral fibers. It is emphasized that the ratio of acid oxides contained in the charge to the main oxides is the main factor influencing the operational resistance of mineral fibers, as well as the energy intensity of their production. A hypothesis has been put forward and confirmed that the operational resistance of a fiber depends on the content of heavy metals (their oxides) in the initial charge. Determination of the elemental composition of stone wool samples was carried out by X-ray fluorescence analysis. Conducted samples with a different acidity module of the study, show, that the fibers are safe by radiation indices, and their operational resistance can be affected by heavy metal oxides. It is substantiated that the durability of building systems in which mineral wool products are used as thermal insulation is determined by the properties of mineral wool products, the literacy of design solutions and the quality of installation. The properties of mineral wool products, including their operational resistance, depend on the properties of mineral fibers and the observance of technological regimes both on the fact of the most complete curing of the binder and on the features of formation of the volume-oriented structure of the mineral wool carpet.
\end{abstract}

\section{Introduction}

Energy efficiency is a comprehensive indicator of the appropriateness of use of certain building systems, including the following evaluation criteria [1, 2]:

- the cost of ensuring the safety of comfortable conditions in the premises with the use of specific systems that form the insulating shell of these premises;

- durability of construction systems in specific operating conditions;

- the cost of installing insulation in a particular construction system;

- the cost of manufacturing heat insulation materials, reduced to a unit of insulated surface.

\footnotetext{
*Corresponding author: medvedev747@yandex.ru
} 
The provision of comfortable conditions assumes the optimization of the heat consumption for heating the premises during the cold season and the consumption of electricity for air conditioning during the hot season. Existing types of thermal insulation materials (based on mineral fibers or foamed plastic) allow to solve these problems with different degrees of efficiency.

An important factor is fire safety. In our country, the fundamental industry document is Federal Law No. 123-FZ "Technical Regulations on Fire Safety Requirements". Foamed plastics are combustible material, so their use in insulation systems is limited to additional requirements and special design solutions. Most types of products based on mineral wool are classified as non-combustible materials, which is why this group of materials has become a further object of research.

The provision of safety is determined by the possibility of releasing harmful substances during current operation. This factor is assessed by sanitary standards and the maximum permissible concentration of harmful substances (MPC). Harm to mineral wool for health is associated with the release of phenol. Phenol is not present in mineral fibers, however it is present in the composition of polymer resin binders. The production of mineral wool products uses a modern high-quality binder - resole resins. Resin is the basis of the binder. The content of binder in the product is on average 3,3\%. In a quality product, the phenolformaldehyde resin is in a solid bound state and is not released during the entire production period. If there are technological disruptions during production, it is not possible to completely polycondensate the binder and to isolate phenol during operation.

The cost of installing a thermal insulation in a particular construction system is determined by the thickness of the thermal insulation layer, determined from the thermotechnical calculation of the structure. The thicker the thermal insulation layer, the higher the thermal resistance of the insulation system, but also the higher the cost of thermal insulation, as well as the subconstruction on which it (thermal insulation) is mounted.

Products made of mineral wool are one of the most used heat-insulating materials in domestic construction. Properties of these products are primarily determined by two factors: the properties of mineral fibers (including the composition of the charge, the technology of melting and processing of the melt) and the technology of manufacturing products themselves $[3,4]$. The characteristics of the mineral fiber and its melting and blowing characteristics depend on the chemical composition of the fiber, which determines both its acidity modulus (fiber quality) and the viscosity modulus (melting conditions). Therefore, determining the elemental composition of fibers is an urgent task. The issue of the ecological safety of building materials and their radiation safety, remains always important $[5,6]$.

According to existing methods, including normative, the fiber resistance is evaluated by its acidity modulus $(\mathrm{Mk})$ equal to the ratio of acid $\left(\mathrm{SiO}_{2}+\mathrm{Al}_{2} \mathrm{O}_{3}\right)$ and basic oxides $(\mathrm{CaO}+$ $\mathrm{MgO}$ ) contained in the fiber [7, 8]. The higher the ratio, the fiber is considered more resistant to aggressive enviroment. Note that if before 1990 the products were manufactured with Mk 1,1-1,4 and their durability is not more than 10 years, now they are manufactured with Mk 1,6-2,1 and the durability of such products exceeds 20 years [9, 10].

Without questioning the normative methods and results of practical application of materials, the authors put forward the hypothesis that one of the factors of high resistance of mineral fibers is their elemental composition, in particular, the content of heavy metals.

\section{Experimental section}

Determination of the elemental composition of mineral wool samples was carried out by Xray fluorescence analysis (XRF). The RFA method is based on excitation of the atoms of the elements contained in the analyzed sample and measuring the intensity of the emerging 
characteristic X-ray radiation of excited atoms by means of spectrometric equipment [11, 12].

Currently, there is a fairly large number of serially produced automated complexes for multi-element XRF. Their range of application is very wide. This ecology, geology, metallurgy, medicine, biology, agriculture, food industry, criminalistics and any other area where a highly sensitive express multi-element analysis of the composition of samples is required.

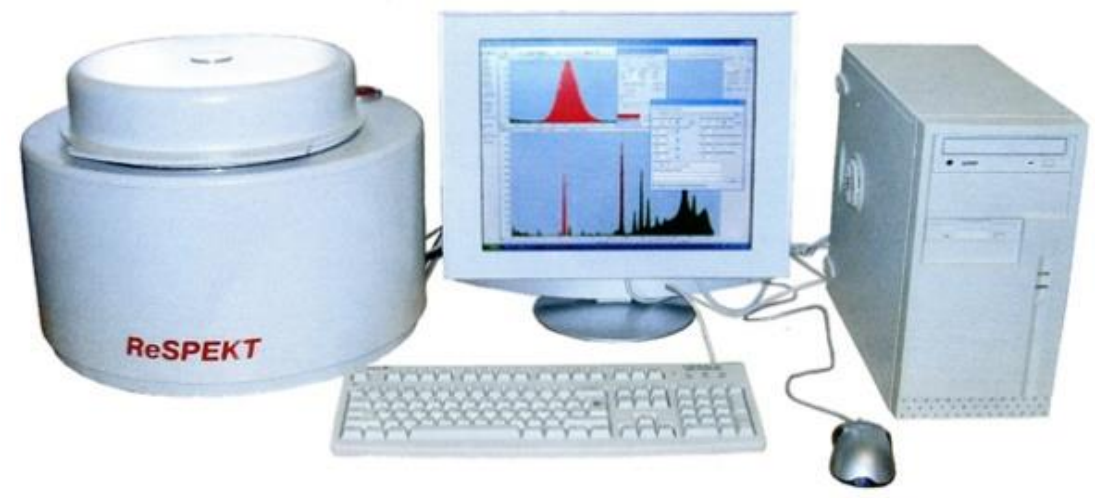

Fig.1 X-ray spectrometer "ReSPECT"

The experiment was carried out with the help of the spectrometer of the elemental composition of the substance "ReSPECT" (Figure 1), in the laboratory of physical methods of analysis by the Russian State Geological Prospecting University (RSGPU) [13, 14]. As the primary exciting radiation in this device, the radiation of an X-ray tube with a silver anode is used. The limiting radiation power of the tube is $120 \mathrm{~W}$. The water cooling system of the $\mathrm{X}$-ray tube is closed.

Secondary X-ray radiation is detected by a semiconductor Si-Pin detector with a resolution of $150 \mathrm{eV}$. In one measurement, it is possible to simultaneously determine 20-25 elements (from $\mathrm{Al}$ to $\mathrm{U}$ ). The measurement process is fully automated. The limit of element detection in solid samples is $\left(10^{-3}-10^{-4}\right) \%$. The range of detectable concentrations is from $0,0001 \%$ to $100 \%$. In the analysis, a sample of rock wool with mass nearly $1 \mathrm{~g}$ was placed in a cuvette with a base of a thin polypropylene film, the cuvette was placed in a carousel calculated for 16 samples (Fig. 2).

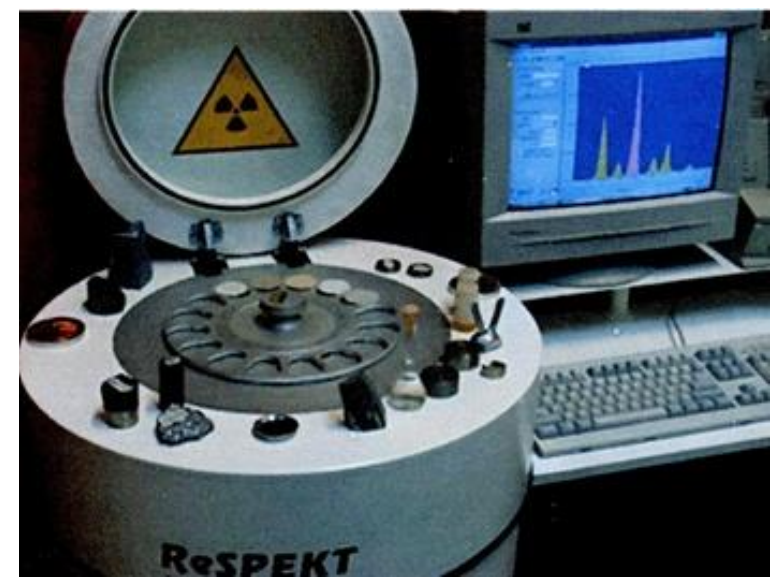

Fig.2 The appearance of the camera with a removable carousel to accommodate 16 samples 


\section{Results section}

The accumulation and processing of spectrometric information is carried out by a personal computer with a built-in single-board spectrometer, which also provides low-voltage and high-voltage power to the detector. The X-ray spectrum processing program identifies the peaks of the elements and determines their areas, which are proportional to the concentrations of the analyzed elements. The result of the processing is a file containing a list of the elements that make up the sample and their concentration.

Table 1 shows the results of measurements four samples of mineral wool, carried out on the spectrometer "ReSPECT".

Established presence in fiber, and consequently, in the initial charge, elevated concentrations of the following metals: $\mathrm{K}, \mathrm{Ca}, \mathrm{Ti}, \mathrm{Mn}, \mathrm{Fe}$.

Table 1. The content of metals in various samples of mineral wool

\begin{tabular}{|l|c|c|c|c|c|c|c|c|c|}
\hline Sample & $\mathrm{K}$ & $\mathrm{Ca}$ & $\mathrm{Ti}$ & $\mathrm{Cr}$ & $\mathrm{Mn}$ & $\mathrm{Fe}$ & $\mathrm{Cu}$ & $\mathrm{Zn}$ & $\mathrm{Sr}$ \\
\hline Isover & 2,6 & 23,8 & 0,18 & 0,007 & 0,58 & 0,96 & 0,004 & 0,01 & 0,008 \\
\hline Izoplet & 2,4 & 26,3 & 1,56 & 0,013 & 0,15 & 6,17 & 0,005 & 0,005 & 0,0036 \\
\hline Technonicol & 3,14 & 46,16 & 1,84 & 0,02 & 0,32 & 0,96 & 0,003 & 0,01 & 0,06 \\
\hline Rocwell & 3.86 & 47,6 & 2.7 & 0,034 & 0,37 & 9,65 & 0,024 & 0,01 & 0,034 \\
\hline
\end{tabular}

\section{Discussion section}

Effective specific activity of natural radionuclides in building materials (raw materials) extracted from their deposits (crushed stone, gravel, sand, butt and sawed stone, cement and brick raw materials, etc.), or a by-product of production, in industrial waste used for manufacture of building materials (ash, slag, etc.), for materials used in the construction (reconstruction, overhaul) of residential and public buildings should not exceed $370 \mathrm{~Bq} / \mathrm{kg}$. This indicator corresponds to 1 class SanPiN 2.6.1.2800-10 «Hygienic requirements for limiting exposure of the population due to natural sources of ionizing radiation».

The effective specific activity of natural radionuclides is calculated by the formula:

$$
A_{\text {eff }}=A_{R a}+1,3 \cdot A_{T h}+0,085 \cdot A_{K}
$$

where $A_{R a}$ and $A_{T h}$ are the specific activities of radium and thorium in equilibrium with the remaining members of the uranium and thorium series, $\mathrm{A}_{\mathrm{eff}}{ }^{40} \mathrm{~K}$ is the specific activity of the potassium- 40 isotope $(\mathrm{Bq} / \mathrm{kg})$. The measurements were carried out on an installation with a semiconductor detector of extremely pure germanium from ORTEC, measuring time $11800 \mathrm{~s}$.

When measuring a sample of mineral wool, the following results were obtained: $A_{R a}=$ $129,5 \mathrm{~Bq} / \mathrm{kg}, \mathrm{A}_{\mathrm{Th}}=30 \mathrm{~Bq} / \mathrm{kg}, \mathrm{A}_{\mathrm{K}}=95 \mathrm{~Bq} / \mathrm{kg}$.

Thus, $A_{\text {eff }}=129,5+1,3 \cdot 30+95 \cdot 0,085=171,5 \mathrm{~Bq} / \mathrm{kg}$, which is two times less than the maximum allowable value and makes it possible to reliably classify said products to the first class.

Along with the increase in $\mathrm{Mk}$, an increase in the content of acidic oxides (and primarily $\mathrm{Al}_{2} \mathrm{O}_{3}$ ) leads to an increase in the viscosity of the melt, which entails a decrease in productivity and a deterioration in the conditions of fiber formation.

In this regard, when choosing the composition of the charge, one has to search for the optimal solution: on the one hand, not to allow too much viscosity in order to avoid dis- 
turbance of the technological process, on the other hand, to not allow low content of acid oxides in the charge to the detriment of the mineral wool longevity.

When solving the first part of the problem, we must take into account not only the acidity modulus $\mathrm{M}_{\kappa}$, but also the viscosity modulus $\mathrm{M}_{\mathrm{B}}$, which more accurately characterizes the melt viscosity. When calculating $\mathrm{M}_{\mathrm{B}}$ the molecular quantities of all oxides are found $\mathrm{M}_{\mathrm{R}_{\mathrm{m}} \mathrm{O}_{\mathrm{n}}}$, for which the amount of each of them in \% by mass is divided by the molecular weight of this oxide. Then it is calculated by the formula

$$
\mathrm{M}_{\mathrm{B}}=\frac{\mathrm{M}_{\mathrm{SiO}_{2}}+2 \cdot \mathrm{M}_{\mathrm{Al}_{2} \mathrm{O}_{3}}}{2 \cdot \mathrm{M}_{\mathrm{Fe}_{2} \mathrm{O}_{3}}+\mathrm{M}_{\mathrm{FeO}}+\mathrm{M}_{\mathrm{CaO}}+\mathrm{M}_{\mathrm{MgO}}+\mathrm{M}_{\mathrm{K}_{2} \mathrm{O}}+\mathrm{M}_{\mathrm{Na}_{2}} \mathrm{O}}
$$

In classical technologies - in the case of a cupola method of production (without heating the air), the upper (critical) limit of the viscosity module, at which the nominal capacity of the melting unit remains, should not exceed 1,2. In the manufacture of cotton wool with the use of bath furnaces, the ultimate viscosity modulus is 1,4 . From the prepared components, the charge is prepared by weighing each component with an automatic weighing batcher.

In modern technologies, using oxygen-laden cupolas and heating the air entering the melting, it became possible to use a charge from Mk to 2.1. But this implies an increase in the melting point from 1300 to $1550^{\circ} \mathrm{C}$ (in some cases up to $1600^{\circ} \mathrm{C}$ ), which greatly increases the energy intensity of the melting of the charge, and, consequently, the production of mineral fiber.

\section{Conclusion}

Thus, the hypothesis has been confirmed that one of the factors of high resistance of mineral fibers is their elemental composition, and in particular the content of heavy metals. Moreover, when controlling the content of some heavy metal oxides, it becomes possible to reduce the melt viscosity modulus while maintaining the acidity modulus and obtaining a fiber with high operational stability (high $\mathrm{Mk}$ ) with an optimized viscosity module $\left(\mathrm{M}_{\mathrm{B}}\right)$, i.e., melting conditions at $1450-1500^{\circ} \mathrm{C}$.

Studies carried out for samples with a different acidity modulus show that the fibers are safe for radiation indices, and their performance resistance can be affected by heavy metal oxides. Further directions of research are the dissemination of the methods used to other types of mineral fibers, such as glass and basalt, to check the presence of radioactive isotopes in the fibers, and also to study the effect of heavy metal oxides on the properties of the basalt rock melts and mixtures of various compositions.

\section{References}

1. B. Rumyantsev, A. Zhukov, T. Smirnova Internet-Vestnik VolgGASU. 43 (2014)

2. A. Zhukov, T. Smirnova, D. Zelenshchikov, A. Khimich, Adv. Mat. Res 838-841 196200 (2014)

3. A. Zhukov, E. Bobrova, T. Smirnova, Adv. Mat., Str. and Mech. Eng. 1077 109-112 (2015)

4. B. Rumyantsev, A. Zhukov Basalt fiber and woven materials on its basis, N. of Hig. Edu. Inst. Tech. of Tex. Ind. 3 114-116 (2017)

5. B. Rumiantcev, A. Zhukov, D. Zelenshikov, A. Chkunin, K. Ivanov, Y. Sazonova, MATEC Web of Conf. 86 (2016) 
6. B. Rumiantcev, A. Zhukov, E. Bobrova, I. Romanova, D. Zelenshikov, T. Smirnova, MATEC Web of Conf. 86 (2016)

7. A. Zhukov, T. Smirnova, D. Zelenshchikov, A. Adv. Mat. Res. 838-841 196-200 (2014)

8. I. Gnip, S. Vaitkus, V. Kersulis, S. Vejelis, Mech Time Depend Mater 16 31-46 (2012)

9. A. Zhukov, E. Bobrova, D. Zelenshchikov, R. Mustafaev, A. Adv. Mat., Str. and Mech. Engineering. 1025 - 1026 1031-1034 (2014)

10. M. Bezdenezhnykh, E. Munieva, A. Zhukov, Building materials and ecology, Persp. of sc. 11 33-36 (2017)

11. I. Tolokonnikov, Atom. 95 69-70 (2003)

12. A. Medvedev, A. Poserenin, Min. Info. and an. Bul. 11 115-124 (2016)

13. A. Medvedev, M. Gurvich, A. Poserenin, The application spectrometr ReSPECT for analysis of the element composition of minerals, rocks and ores Mat. of XII Int. sc. and prac. conf. «New ideas in earth sciences» 147 (2015)

14. A. Medvedev, A. Zhukov, E. Bobrova, E. Petrovskiy, D. Tuchaev, Sc. and business: ways of dev. 10 35-38 (2017) 